\title{
Alcohol Intake Investigation of Adult Rats Based on Sperm Parameters
}

\author{
Choirul Anam ${ }^{1 *}$, Agung Pramana Warih Marhendra², Sri Rahayu² \\ ${ }^{1}$ Master Program of Biology, Faculty of Mathematics and Natural Sciences, University of Brawijaya, Malang, Indonesia \\ ${ }^{2}$ Department of Biology, Faculty of Mathematics and Natural Sciences, University of Brawijaya, Malang, Indonesia
}

\begin{abstract}
The prevalence of alcohol consumption is high among adult males during the reproductive period. The current study aimed to evaluate the impact of chronic administration ethanol on the quality of sperm in the rats. Twelve healthy Wistar male albino rats were randomly divided into 2 groups to represent the 2 phase duration. The first phase lasted 21 days and the second phase lasted 49 days. In each phase, the animals were separated into subgroups: A and B. Subgroup A represented control that received distilled water while subgroup B represented animals that received 7 $\mathrm{mL} . \mathrm{kgBW}^{-1}$ of $30 \%$ ethanol per day, thrice a week. The data were analyzed using ANOVA $(P<0.05)$. There is no significant difference in sperm concentration and viability. However, there is a significant difference in the motility of spermatozoa between the control group and ethanol-treated group. Thus, the study indicates that ethanol administration may disturb the sperm motility and have no clear effect on its concentration and viability.
\end{abstract}

Keywords: alcohol consumption, reproductive function, sperm quality.

\section{INTRODUCTION}

Ethanol has been now reported to be among the most widely abused drug which may suppress reproductive function and sexual behavior in laboratory animals and humans. Both acute and chronic ethanol administration exerts a dual effect on the hypothalamic-pituitary-gonadal axis by directly preventing testicular steroidogenesis and by inhibiting the release of Lutenizing Hormone-Releasing Hormone (LHRH) [1].

Ethanol enlarges oxidative stress through the generation of oxygen-free radicals and lipid peroxidation on its metabolism in the body [2], mainly because ethanol administration can cut down the antioxidant cells such as Superoxide Dismutase (SOD), Catalase (CAT), and Glutathione Peroxidase (GPx). Undoubtedly, oxidative stress is one of the factors playing a key role in various pathways of alcohol-induced damage. Oxidative stress involves many conditions that stimulate either the production of Reactive Oxygen Species (ROS) or a decline in antioxidant defenses. During ethanol metabolism, the detrimental effects of ethanol not only generates a massive ROS but also form acetaldehyde. Ethanol is also oxidized by cytochrome P450 to acetaldehyde, which increases ROS, with concomitant changes in redox balances [3]. Acetaldehyde can weaken the activity in the hypothalamus with its receptors in the pituitary in the process of releasing $\mathrm{LH}$ and

*Correspondence address:

Choirul Anam

Email : choirulanam32260@gmail.com

Address : Dept. Biology, University of Brawijaya, Veteran Malang, Malang 65145. damaging the function of protein kinase $\mathrm{C}$, a key enzyme in LH production [4]. Meanwhile, reactive oxygen species result in lipid peroxidation in spermatogenic cell membranes which is the cause of cell apoptosis [5].

Alcohol abuse has been considered as one of the problems associated with poor semen production and sperm quality [6]. Alcohol consumption in men has been associated with testicular atrophy $[7,8]$, reducing in sperm count, in the percentage of motile spermatozoa and the total of spermatozoa with normal morphology $[9,10]$. Additionally, the negative impact of chronic alcoholism on sperm parameters was significantly decreased in semen volume, sperm count, motility and number of morphologically normal spermatozoa [7].

In rats, ethanol caused a significant rise in the tissue and plasma lipid peroxidation and decrease the tissue and plasma antioxidants such as superoxide dismutase, glutathione, catalase, peroxidase, vitamin C and vitamin E [11]. Dosumu [12] reports that administration of $30 \%$ alcohol in adult rats has made an impact on the reduction of spermatogenic cells, tubular atrophy, crosssectional areas, and tubular diameter. Testicular weight, sperm motility and sperm count were also declined. Hormonal assay indicated a severe reduction in the levels of testosterone. Therefore, this study was undertaken to determine the effects of chronic administration of ethanol followed by abstinence on sperm parameters of adult rats. 


\section{MATERIALS AND METHODS Research Materials}

Twelve healthy Wistar male albino rats (average weight 280-340 g) were housed in the animal holdings of the Animal Physiology Laboratory, Faculty of Mathematics and Natural Sciences, University of Brawijaya, in well ventilated plastic cages with a $12 / 12 \mathrm{~h}$ light/dark cycle at $21-24^{\circ} \mathrm{C}$ and free access to rodent food and water. Approval for the study was obtained from the Animal Care and Use Committee of University of Brawijaya number 1079-KEP-UB. Thirty percent $(30 \%)$ of ethanol prepared from absolute ethanol (99.86\%) Smart Lab (PT. Smart Lab, Indonesia).

\section{Research Methods}

Animals were randomly divided into 2 groups to represent the 2 phase duration. The first phase lasted 21 days and the second phase lasted 49 days. In the previous result [12], administration of ethanol $30 \%$ for 14 days could reduce the sperm count, motility and morphology and the intake of 21 days ethanol was considered to provide more significant results due to longer ethanol administration. The second factor was the time required for the formation of rat spermatozoa was 49 days [13]. In each phase, the animals were divided into subgroups: $A$ and $B$. Subgroup $A$ represented control that received distilled water while subgroup B represented animals that received $7 \mathrm{~mL}^{\mathrm{kgBW}}{ }^{-1}$ of $30 \%$ ethanol per day, thrice a week [14] in details:
A1 (Control group 1) : distilled water
B1 (Treatment group 21 days) : ethanol $30 \%$
A2 (Control group 2) : distilled water
B2 (Treatment group 49 days) : ethanol $30 \%$

At the end of each phase, rats were sacrificed. Right after, testes and epididymis harvested for histological studies.

\section{Sperm Analysis}

The epididymis was placed in a Petri dish containing $500 \mu \mathrm{l}$ PBS and cut into pieces using scissors to allow the spermatozoa to come out from the epididymis. Sperm quality was determined by the concentration, motility, and viability.

Sperm concentration was counted by using an improved Neubauer hemocytometer. Sperm suspensions were directly diluted $1: 20$ in a diluting solution of $\mathrm{Na}_{2} \mathrm{HCO}_{3}$ and formalin in distilled water. The results of dilution were then put into the counting chamber and the number of sperm was counted. Sperm motility was analyzed by taking sperm suspensions in the Petri dish using a micropipette and dropping 1 drop on the glass object. Furthermore, it was observed using a light microscope with 400x magnification. Sperm viability measurement was done by using eosin (EO) dye exclusion test. The sperm suspension was mixed with $10 \mu \mathrm{L}$ of eosin-nigrosin dye. A thin smear of sperm was prepared after $1 \mathrm{~min}$ and the number of viable sperm was determined out of 200 sperm in 10 microscopic fields (400x). The live spermatozoa cells were white and the dead were stained red [14].

\section{Statistical Analysis}

The data obtained from all the groups were compiled and statistically analyzed also presented as mean \pm standard deviation. Differences between groups were compared using one-way ANOVA with $p<0.05$ considered significant and followed by Tuckey's Post hoc test.

\section{RESULTS AND DISCUSSION}

The count of spermatozoa can be seen in Table 1. The statistical test of spermatozoa concentration shows that there is no significant difference in each treatment $(p>0.05)$.

Table 1. Sperm Concentration

\begin{tabular}{|c|c|}
\hline Treatment Group & $\begin{array}{l}\text { erm Concentration } \\
\left(10^{6} \cdot \mathrm{mL} \pm \mathrm{SD}\right)\end{array}$ \\
\hline A1 & $74.72 \pm 10.75$ \\
\hline $\mathrm{A} 2$ & $91.66 \pm 7.94$ \\
\hline B1 & $53.61 \pm 22.21^{*}$ \\
\hline B2 & $91.66 \pm 7.94$ \\
\hline \multicolumn{2}{|l|}{$\begin{array}{l}\text { Notes: } \\
*=\text { Significant }\end{array}$} \\
\hline A1 (Control group 1) & : distilled water \\
\hline A2 (Control group 2) & : distilled water \\
\hline B1 (Treatment group 21 days) & : ethanol 30\% \\
\hline B2 (Treatment group 49 days) & : ethanol $30 \%$ \\
\hline
\end{tabular}

The results of this study indicate a decrease in spermatozoa concentration after alcohol intake for 21 days and it reached the lowest level of the treatment. Sperm concentration in ethanol treatments for 21 days showed a lower value compared to the control group. Whereas ethanol administration for 49 days showed the same results compared to the control group.

However, there was no significant difference between all treatments. The use of ethanol for the longer term does not affect sperm count. Ethanol does not significantly affect the concentration of spermatozoa, because the metabolism of ethanol in the rat body does not 
produce excessive amounts of ROS, so oxidative stress conditions do not occur. The body's natural antioxidants can reduce free radicals so that no cell death occurs. This is supported by the previous study that explained sperm concentration, total sperm count, and percentage of spermatozoa with normal morphology were negatively associated with increasing habitual alcohol intake [15]. No statistical differences in seminal parameters found between the degrees of alcohol consumption and control [16].

\section{Sperm Motility}

There are significant differences between treatment groups $(p>0.05)$ as shown in Table 2 . The table shows that treatment groups of ethanol administration both in 21 days and 49 days have sperm motility level lower than the control group. This study proves that ethanol impaired motility of spermatozoa. The percentage of sperm motility level of the control group in 21 days was $74.66 \%$ and 49 days was $77.33 \%$. This level indicates that the control group belongs to the normal category (>50\%). While the sperm level of the treatment group was $37.33 \%$ and $41.66 \%$ shows that there were subfertile category and ethanol play an important role in this [17]. A decline of sperm motility can be affected by disrupted of the spermatogenesis in testes and sperm maturation in epididymis [18].

Table 2. Sperm Motility

\begin{tabular}{|c|c|}
\hline Treatment Group & Sperm Motility (\%₫ SD) \\
\hline $\mathrm{A} 1$ & $74.66 \pm 3.51$ \\
\hline $\mathrm{A} 2$ & $77.33 \pm 2.88$ \\
\hline B1 & $37.33 \pm 3.05^{*}$ \\
\hline B2 & $41.66 \pm 7.02 *$ \\
\hline \multicolumn{2}{|l|}{ Notes: } \\
\hline \multicolumn{2}{|l|}{$*=$ Significant } \\
\hline \multicolumn{2}{|l|}{ SD = Standard Deviation } \\
\hline A1 (Control group 1) & : distilled water \\
\hline A2 (Control group 2) & : distilled water \\
\hline B1 (Treatment group 21 days) & : ethanol 30\% \\
\hline B2 (Treatment group 49 days) & : ethanol $30 \%$ \\
\hline
\end{tabular}

The ethanol-related decline in spermatozoa motility in the treated groups is one of a range of indicators that chronic ethanol consumption may endanger the structural integrity of the spermatozoa through the mitochondrial pathway. Ethanol makes mitochondria less functional by carrying out mitochondrial protein synthesis [19]. This suppresses oxidative phosphorylation of spermatozoa cells [20] leading to enzyme inactivation [21]. Ultimately, this results in numerous alterations within the mitochondria may stimulate both necrotic and apoptotic cell death.

Ethanol affects mitochondrial function. Mitochondria produce ATP needed for the movement of the flagella of sperm cells. Hence, a reduced or impaired mitochondrial function will prevent sperm motility as observed in the alcohol-treated groups of this study. It reported that mitochondria are targets for oxidative stress-related signal control cell fate [22].

\section{Sperm Viability}

The percentage of spermatozoa viability shown in Table 3. There were no significant differences between the ethanol-treated group compared to the control group $(p>0.05)$. The highest level of viability of sperm was A1. This level was far from the other groups, while the lowest level was reached by B1 about $42 \%$.

Table 3. Sperm Viability

\begin{tabular}{lc}
\hline \multicolumn{1}{c}{ Treatment Group } & Sperm Motility (\% \pm SD) \\
\hline A1 & $87.76 \pm 9.25$ \\
B1 & $61 \pm 1.34$ \\
B2 & $42.31 \pm 10.66^{*}$ \\
Notes: & $50.33 \pm 6.88$ \\
$*^{*}$ = Significant & \\
SD = Standard Deviation & \\
A1 (Control group 1) & $:$ distilled water \\
A2 (Control group 2) & $:$ distilled water \\
B1 (Treatment group 21 days) & $:$ ethanol 30\% \\
B2 (Treatment group 49 days) & $:$ ethanol 30\%
\end{tabular}

Sperm viability in ethanol treatments for 21 days showed a lower percentage compared to the control group. As well as giving ethanol for 49 days also gave lower results than the control group. However, the decrease in the percentage of viability in the ethanol treatment groups did not show a significant difference with the control rats.

Living spermatozoa are not able to absorb color because the membrane permeability is still in good condition so that eosin-nigrosin. Dye cannot enter the cell. Conversely, eosin-nigrosin dye can enter the dead spermatozoa cells which result in cells appearing red. This is because the permeability of the membrane decreases so that dyes easily enter the cell [23]

Membrane damage occurs due to the results of ethanol metabolism that produce free radicals, which can damage membrane integrity and permeability [24]. Based on the results, 30\% of ethanol did not produce excessive ROS production, which later damages the cell membrane. So that lipid peroxidation becomes 
reduced, which causes decreased sperm cell death.

Within normal physiologic conditions, internal antioxidants help to maintain a low level of oxidative stress in the semen [25]. Nevertheless, if the production of free radicals is excessive, then the body's natural antioxidants are not able to neutralize, which results in an imbalance between antioxidants and free radicals. In this case, antioxidants such as superoxide dismutase, catalase, glutathione peroxidase were thought to play a role suppresses free radicals by giving hydrogen atoms which cause neutralized ROS [26].

Percentage of survived (lives) spermatozoa was higher compared to the percentage of motility for all treatments. This is a normal condition because immobile spermatozoa do not necessarily die. Spermatozoa that only move slowly, but still alive, it won't absorb eosin color. Partodiharjo [27] suggests that the spermatozoa that not moving are not necessarily dead. So does the one that not adsorb the color, while on interpretation with the basis of moving and not moving is considered immotile.

\section{CONCLUSION}

The $30 \%$ ethanol induction did not have a sharp impact on sperm concentration and viability levels. However, the percentage of motility spermatozoa was different between the ethanol-treated group and control group. It reduces sperm motility quite significantly.

\section{REFERENCES}

[1] Wang, J.H., R.G. Batey, J. George. 2006. Role of ethanol in the regulation of hepatic stellate cell function. World J. Gastroenterol. 12(43). 6926-6932.

[2] World Health Organization. 2004. WHO global status report on alcohol. Available at: http://www.who.int/entity/substance_abus e/publication/global_status_report_2004_o verview.pdf.

[3] World Health Organization. 2018. Global status report on alcohol and health 2018. Available at: https://www.who.int/ substance_abuse/publications/global_alcoh ol_report/en/.

[4] Little, P.J., M.L. Adams, P.J. Cicero. 1992. Effects of alcohol on the hypotalamicpituitary-gonadal axis in the developing male rat. J. Pharmacol. Exp. Ther. 263. 1056-1061.
[5] Nordman, R., C. Ribiere, H. Rouchah. 1990. Ethanol induced lipid peroxidation and oxidative stress in extra hepatic tissues. Alcohol. 25. 231-237.

[6] Zima, T., L. Fialova, O. Mestek, M. Janebova, J. Crkovska, I. Malbohan. 2001. Oxidative stress, metabolism of ethanol and alcohol-related disease. J. Biomed. Sci. 8. 59-70.

[7] Rachdaou, N., \& K.S. Dipak. 2013. Effects of alcohol on the endocrine system. Endocrinol. Metab. Clin. North Am. 42. 593-615.

[8] Talabi, A.R, A.A. Sarchesmeh, M.A Khalili, N. Tabibreyad. 2011. Effects of ethanol consumption on chromatin condensation and DNA integrity of epididymal spermatozoa in rat. Alcohol. 45(4). 403-409.

[9] Muthusami, K.R., P. Chinnaswamy. 2005. Effect of chronic alcoholism on male fertility hormones and semen quality. Fertil. Steril. 84(4). 919-924.

[10] Anderson, K., V. Nisenblat, R. Norman. 2010. Lifestyle factors in people seeking infertility treatment - a review. Aust. $\mathrm{N} Z \mathrm{~J}$ Obstet. Gymaecol. 50. 8-20.

[11] Mani, V., A. Sivaranjani, I.S. Aktarul, N. Nalini. 2016. Antioxidant and antiinflammatory role of zingerone in ethanol-induced hepatotoxicity. Mol. Cell Biochem. 421. 169-181.

[12] Dosumu, O.O., A.A.A. Osinubi, F.I.O. Duru. 2014. Alcohol induced testicular damage: can abstinence equal recovery. Middle East Fertil. Soc. J. 19. 221-228.

[13] Susetyarini, E. 2010. Uji aktivitas tanin daun beluntas (Pluchea indica) terhadap potensi fertilisasi spermatozoa tikus putih jantan. Research Report. Research Center, University of Muhammadiyah Malang. Malang.

[14] Donnelly, G.P., N. McClure, M.S. Kennedy, S.E. Lewis. 1999. Direct effect of alcohol on the motility and morphology of human spermatozoa. Andrologia. 31. 43-47.

[15] Dosumu, O.O., O.B. Akinola, E.N. Akang. 2012. Alcohol-induced testicular oxidative stress and cholesterol homeostasis in rats the therapeutic potential of virgin coconut oil. Middle East Fertil. Soc. J. 17. 122-128.

[16] Eskenazi, B., A.J. Wyrobek, E. Sloter, S.A. Kidd, L. Moore, S. Young, D. Moore. 2003. The association of age and semen quality in healthy men. Hum. Reprod. 18. 447-454. 
[17] Jensen, T.K., M. Gottschau, J.O. Madsen, A.M. Andersson, T.H. Lassen, N.E. Skakkebæk, S.H. Swan, L. Priskorn, A. Juul, N. Jørgersen. 2014. Habitual alcohol consumption associated with reduced semen quality and changes in reproductive hormones; a cross-sectional study among 1221 young Danish men. BMJ Open. 4. 1-9.

[18] Ana, C.M., I.M. Rosa, E. Daniel, S. Daniel, F.C. Marta, D.R. Ruben. 2004. Effects of alcohol and cigarette consumption on human seminal quality. Fertil. Steril. 82. 374-377.

[19] Johnson, M.H. 2007. Essential reproduction. Blackwell Publishing. Massachusetts.

[20] Creasy, D.M., R.E. Chapin. 2013. Haschek and Rousseaux's handbook of toxicologic pathology, $3^{\text {rd }}$ Ed. Reproductive and Developmental Toxicology. Available at: https://www.sciencedirect.com/topics/med icine-and-dentistry/sperm-motility.

[21] Coleman, W.B., C.C. Cunningham. 1991. Effect of chronic ethanol consumption on hepatic mitochondrial transcription and translation. Biochem. Biophys. Acta. 1058. 178-186.

[22] Sastre, J., G. Serviddio, J. Pereda, J.B. Minana, A. Arduini, G. Vendemiale, G. Poli, F.V. Pallardo, J. Vina. 2007. Mitochondrial function in liver disease. Front. Biosci. 12. 1200-1209.

[23] Arifiantini, I., T.L. Yusuf, N. Graha. 2005. Longivitas dan recovery rate pasca thawing semen beku sapi Fresian Holstein menggunakan bahan pengencer yang berbeda. Buletin Peternakan. 29(2). 53-61.

[24] Maneesh, M., H. Jatalekshmim, Sanjiba, D., Amit, C., D.M. Vasundevan. 2005. Role of Oxidative Stress in Ethanol Induced Germ Cell Apoptosis-An Experimental Study in Rats. Indian Journal of Clinical Biochemistry. 20(2), 62-67.

[25] Argawal, A., Shyam, S.R.A. 2004. Review Oxidants and antioxidants in human fertility. Middle East Fertility Society Journal. 9(3). 187-197.

[26] Choudhary, R., V.K. Chawala, N.D. Soni, K. Jayant, R.K. Vyas. 2010. Review article oxidative stress and role of antioxidants in male infertility. Pak. J. Physiol. 6(2). 54-59.

[27] Partodiharjo, S. 1992. Ilmu reproduksi hewan. Mutiara Publisher. Jakarta. 